\title{
Comment on: EARly Clinical manifestations of Vibrio necrotising fasciltis
}

Singapore Med J 2018; 59(8): 449 https://doi.org/10.11622/smedj.2018098

Dear Sir,

The case series reported by Koh et al ${ }^{(1)}$ raised important issues concerning infections from Vibrio vulnificus (V. vulnificus). We would like to expand on this report regarding other conditions from this organism apart from necrotising fasciitis. This bacterium is more commonly associated with fatal foodborne disease, (septicaemia) events from consuming uncooked or raw shellfish (e.g. oysters), rather than site-specific infections. ${ }^{(2,3)}$ Historically, the majority (>95\%) of cases reported for $V$. vulnificus present as a foodborne disease usually involving oysters or mussels and have a case fatality rate of around $50 \% .^{(2,4)}$

However, at least one report suggested that wound infection is gaining in importance. ${ }^{(3)}$ As noted by Koh et al, the presence of this infectious agent appears to be related to warm water, and its distribution is expanding due to global warming. ${ }^{(2)}$ The majority of clinical cases from V. vulnificus emerge in the summer and are associated with males and brackish water (in estuaries). ${ }^{(5,6)}$ Recently, it has been demonstrated that this microbe can survive year-round in sediment, providing a potential reservoir of infection in some locations, especially where low salinity occurs. ${ }^{(6)}$ It has been suggested that the higher infection rate in males and those over 50 years of age is due to the protective influence of oestrogen from virulence. ${ }^{(2,4)}$ Studies have shown that hormones can influence a microbe's virulence through various mechanisms, including quorum sensing (signalling). ${ }^{(4,7)}$ Global warming, ageing populations, sediment acting as a reservoir and an observed increase in wound infections from this microbe suggest a need for heightened concern. These phenomena indicate that $V$. vulnificus has become a global emerging disease, especially in coastal areas. ${ }^{(6)}$

Yours sincerely,

J H $\underline{\text { Lange }}^{1}$, Luca $\underline{\text { Cegolon }}{ }^{2}$

${ }^{1}$ Envirosafe Training and Consultants, Pennsylvania, United States, ${ }^{2}$ IRCCS Burlo Garofolo, Scientific Directorate, Trieste, Italy. jhlange1@hotmail.com

\section{REFERENCES}

1. Koh THB, Tan JHJ, Hong CC, Wang W, Nather A. Early clinical manifestations of vibrio necrotising fasciitis. Singapore Med J 2018; 59:224-7.

2. Oliver JD. Wound infections caused by Vibrio vulnificus and other marine bacteria. Epidemiol Infect 2005; 133:383-91.

3. Jones EH, Feldman KA, Palmer A, et al. Vibrio infections and surveillance in Maryland, 2002-2008. Public Health Rep 2013; 128:537-45.

4. Motes ML, DePaola A, Cook DW, et al. Influence of water temperature and salinity on Vibrio vulnificus in Northern Gulf and Atlantic Coast oysters (Crassostrea virginica). Appl Environ Microbiol 1998; 64:1459-65

5. Merkel SM, Alexander S, Zufall E, Oliver JD, Huet-Hudson YM. Essential role for estrogen in protection against Vibrio vulnificus-induced endotoxic shock. Infect Immun 2001; 69:6119-22.

6. Huehn S, Eichhorn C, Urmersbach S, et al. Pathogenic vibrios in environmental, seafood and clinical sources in Germany. Int J Med Microbiol 2014; $304: 843-50$.

7. Heng SP, Letchumanan V, Deng CY, et al. Vibrio vulnificus: an environmental and clinical burden. Front Microbiol $2017 ;$ 8:997.

Editor's note: The authors, Koh et al, have declined to respond to the above letter. 